Article

\title{
Optimized Dimensioning and Operation Automation for a Solar-Combi System for Indoor Space Heating. A Case Study for a School Building in Crete
}

\author{
Dimitris Al. Katsaprakakis * and Georgios Zidianakis \\ Wind Energy and Power Plants Synthesis Laboratory, Department of Mechanical Engineering, Technological \\ Educational Institute of Crete, Estavromenos, 71410 Heraklion Crete, Greece; g.zidianakis82@gmail.com \\ * Correspondence: dkatsap@staff.teicrete.gr; Tel.: +30-2810-379-220; Fax: +30-2810-319-478
}

Received: 30 November 2018; Accepted: 3 January 2019; Published: 7 January 2019

\begin{abstract}
This article investigates the introduction of hybrid power plants for thermal energy production for the indoor space heating loads coverage. The plant consists of flat plate solar collectors with selective coating, water tanks as thermal energy storage and a biomass heater. A new operation algorithm is applied, maximizing the exploitation of the available thermal energy storage capacity and, eventually, the thermal power production from the solar collectors. An automation system is also designed and proposed for the realization of the newly introduced algorithm. The solar-combi system is computationally simulated, using annual time series of average hourly steps. A dimensioning optimization process is proposed, using as criterion the minimization of the thermal energy production levelized cost. The overall approach is validated on a school building with $1000 \mathrm{~m}^{2}$ of covered area, located in the hinterland of the island of Crete. It is seen that, given the high available solar radiation in the specific area, the proposed solar-combi system can guarantee the $100 \%$ annual heating load coverage of the examined building, with an annual contribution from the solar collectors higher than $45 \%$. The annually average thermal power production levelized cost is calculated at $0.15 € / \mathrm{kWh}_{\text {th }}$.
\end{abstract}

Keywords: heating and cooling loads; biomass-solar combi systems; buildings energy performance upgrade; solar collectors' simulation; thermal energy storage

\section{Introduction}

\subsection{Solar Radiation for Thermal Energy Production}

Thermal energy constitutes one of the major consumed final forms of energy, accounting for a high percentage of the annual energy consumption balance of a specific consumer. For instance, the thermal energy annual consumption for indoor space conditioning and hot water production in a typical commercial building in United States accounts for more than $40 \%$ of the building's total energy consumption [1].

Thermal energy so far is traditionally produced with electricity or non-renewable fossil fuels (oil, natural gas, biomass etc.). Thermal energy production with electrical devices-maybe apart from heat pumps with Coefficient of Performance higher than 5 constitutes a considerably ineffective process, especially when electricity is produced from thermal power plants. In such cases, the overall efficiency of the whole energy transformation process, starting from the initial chemical primary energy source of the available fossil fuel and ending in the finally consumed thermal energy, can be close to $35 \%$, depending on the thermal generators types involved. This is a typical average efficiency of electrical systems based on thermal power plants, like the one in Crete, although new advances on the thermal generators technologies promise higher efficiencies in the approximate future. On the other hand, 
thermal energy produced locally with oil, gas or solid fuels burners (e.g., coal or biomass), imposes significant gas emissions and atmospheric pollution, which can raise a crucial issue in cases of already burdened urban environments.

Thermal energy production technologies based on Renewable Energy Sources (RES) features as a quite attractive alternative, especially in southern climates (e.g., the Mediterranean basin), with high incident solar radiation density, even during winter. The available thermal energy production technologies from RES include the various types of solar collectors: uncovered, flat plate with/without selective coating, vacuum tubes and concentrating solar collectors.

Concentrating solar collectors, due to the high achieved concentration ratio of the incident solar radiation on the focal line or point, and the subsequent high concentrated thermal power, are used in the so-called solar thermal power plants, aiming at guaranteed electricity production from solar radiation $[2,3]$.

The uncovered solar collectors consist of a set of plastic, dark colored pipelines (usually black). The most usual application of uncovered solar collectors is the swimming pools heating. With uncovered solar collectors and required water temperature in the swimming pool at the range of $25^{\circ} \mathrm{C}$, the use of a swimming pool in warm climates (annual global irradiation on horizontal level higher than $1600 \mathrm{kWh} / \mathrm{m}^{2}$ ) can be extended from April to October. Empirically, the total required solar collectors' area is equal to $80 \%$ of the heated swimming pool's free surface [4-6].

Flat-plate solar collectors are the most widely used solar radiation exploitation technology for the production of thermal energy. The absorptance coefficient of the absorber plate determines the type of the flat-plate solar collectors: black painted or semi-selective coating collectors, with absorptance coefficients at the range of $80 \%$, and selective coating collectors, with absorptance coefficient at $90-95 \%$, while keeping the emissivity coefficient at $5-15 \%$. The flat-plate solar collectors are used for indoor space and water heating $[7,8]$. Selective coating collectors may be also used when higher temperatures are required $[9,10]$.

Vacuum tube solar collectors consist of an absorber surface, introduced inside a vacuum space, aiming at the minimization of the thermal losses with convection from the collector to the ambient. Vacuum tube solar collectors can maintain high efficiency even during adverse weather conditions. They seem ideal for indoor space and water heating in cold climates [11-15]. Additionally, they exhibit the ability to increase significantly the temperature of the working medium (up to $300{ }^{\circ} \mathrm{C}$ ). Consequently, they are used in special industrial applications and generally, in every application that high temperatures are required $[16,17]$.

Finally, a very recent innovation concerning the exploitation of solar radiation are the photovoltaic thermal hybrid solar collectors. These devices exploit solar radiation for both electricity production, acting as a common photovoltaic panel, and for thermal energy production, acting as a flat plate solar collector, cooling, concurrently, through the flow of the working medium in the pipelines, the photovoltaic panel and improving, in this way, its efficiency [18-20]. The total efficiency for both thermal energy and electricity production is increased above $85 \%$, calculated as the ratio of the total electrical and thermal power output versus the incident solar radiation on the total photovoltaic hybrid collector's effective surface.

\subsection{Solar-Combi Systems}

The combination of solar collectors with thermal energy storage tanks and a conventional back-up thermal power production unit (e.g., an oil burner) is known as solar-combi system. In other words, this implementation could be defined as a hybrid power plant for thermal power production. The essential layout of a hybrid thermal power plant is presented in Figure 1. It consists of the following discrete components:

- $\quad$ solar collectors, as base units

- water thermal tanks, as storage units

- a central heating burner, as the back-up unit for guaranteed thermal power production 
- an electronic central control unit, for the supervision and the management of the system's operation

- the hydraulic network, consisting of pipelines, devices and equipment aiming to ensure the secure and effective circulation of the working fluid.

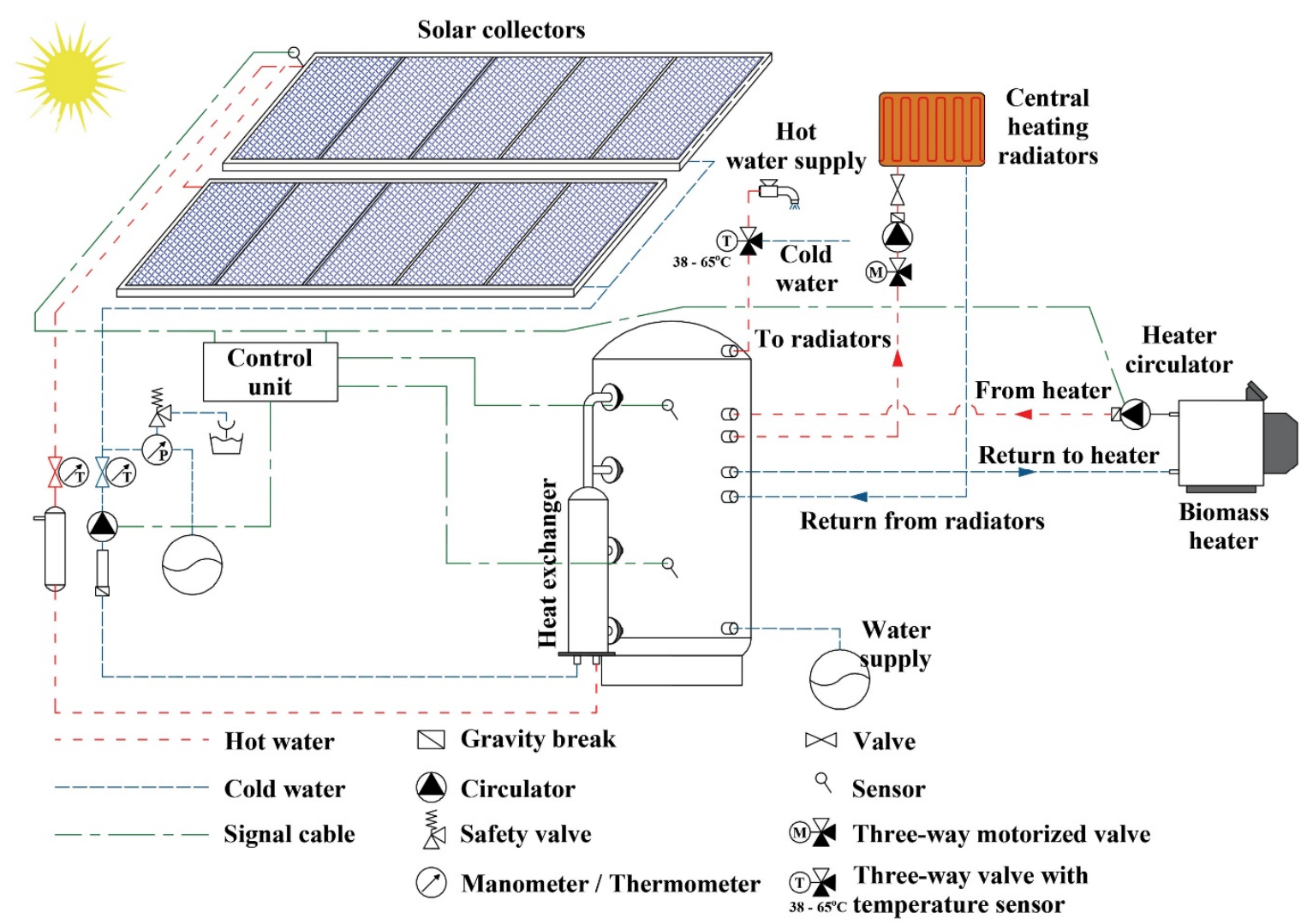

Figure 1. Typical layout of a thermal hybrid power plant.

As with hybrid power plants for electricity production, the ultimate scope of solar-combi systems is the guaranteed coverage of a specific thermal power demand, based on solar collectors, namely on the stochastic availability of solar radiation (primary energy source). This is achieved with the support of thermal storage tanks, which, in most conventional cases are insulated water tanks, equipped with multiple inlets for the concurrent thermal energy storage from different hydraulic networks, supplied by alternative thermal sources. The system is integrated with a conventional thermal power production unit (e.g., an oil burner), acting exclusively as a back-up unit, namely it is utilized only in cases of inadequate available solar radiation and low thermal energy storage level, with regard to the current thermal power demand.

Solar-combi systems constitute a popular subject in the relevant scientific literature. They are usually introduced and investigated for indoor space heating for residential buildings [21-25], while studies have been also executed for school buildings [26], hotels [27], swimming pools heating [28,29], even for central heating district systems [30] and advanced systems for both pure and hot water production [31]. The relevant research has been concentrated on:

- the simulation of their operation, based on specific operation algorithms $[32,33]$

- validation of their performance based on the comparison of both a simulation approach and experimental measurements of the system's operation [34]

- investigation of alternative thermal energy storage technologies, involving phase change materials $[35,36]$

- evaluation of solar-combi systems layouts involving seasonal thermal storage $[23,37,38]$

- evaluation of solar-combi systems performance under different operation conditions [39]. 


\subsection{Content, Scope and Novelties of the Present Article}

The scope of this article is the optimum dimensioning of a solar-combi system for indoor space heating and the introduction of a new operation algorithm, along with its realization system. The overall approach is validated on a high-school building, located in the small town of Arkalochori (5000 permanent inhabitants), in the hinterland of Crete, where remarkable solar radiation is available even during the winter period. Particularly, the study focuses on the following tasks:

- calculation of the building's heating loads

- dimensioning of the solar-combi system, consisting of flat plate solar collectors with selective coating, water thermal energy storage tanks and a biomass heater, aiming at $100 \%$ coverage of the building's heating loads

- annual calculation of the thermal energy production and storage from the involved components of the solar-combi system

- optimization of the system's dimensioning, using as criterion the minimisation of the average annual thermal energy production levelized cost (in $€ / \mathrm{kWh}_{\mathrm{th}}$ ). This cost is calculated as the ratio of the total average annual production cost (including regular annual operation \& maintenance cost and the set-up cost annual amortization) versus the final thermal energy production by the solar-combi system. A detailed definition is provided in relationship (1), Section 3.1.

The above tasks are executed with the support of the TRNSYS software application, regarding the heating loads calculation and the simulation of the solar collectors' performance. The combined operation of the solar collectors, the thermal storage tanks and the biomass heater is executed with simulation applications of the introduced operation algorithm, developed by the authors on the LabVIEW platform. The calculation is executed on hourly average calculation steps and for one whole annual period.

The main challenge with the proposed system was that, due to the size of the building under consideration, the required capacity of the thermal storage facility is considerably increased. The increased thermal energy storage capacity can be met only with the introduction of multiple water thermal storage tanks. Yet, this fact makes the control and the automatic operation of the solar-combi system more complicated, since there should be a flexible and effective automation introduced for the realization of an optimized storage algorithm in the available different storage tanks in order to:

(a) ensure that there will always be hot water available at the appropriate temperature inside a specific thermal tank, to undertake the current thermal power demand.

(b) maximize the thermal energy storage from the solar collectors, even in cases it is provided in relatively low temperatures (e.g., during the very first hours, right after the dawn).

The novelty of this article lays precisely on the development of the operation algorithm of the investigated solar-combi system, configured in order to fulfil the above objectives, and the control system introduced for its realization. The realization process and the corresponding results of the above tasks are presented in the following sections.

\section{Heating Loads Calculation}

\subsection{Location, Background}

The high-school building under consideration (Figure 2) is located in the small town of Arkalochori, in the hinterland of the island of Crete, $25 \mathrm{~km}$ to the south from the city of Heraklion, the capital of the island. The geographical coordinates of the building are $35^{\circ} 09^{\prime} 20^{\prime \prime} \mathrm{N}, 25^{\circ} 16^{\prime} 08^{\prime \prime} \mathrm{E}$. The energy upgrade of the school building from energy performance rank D to B+ was funded by a national-European Union (E.U.) co-funding action, following an open tender posted by the responsible Ministry of Energy in 2011. 


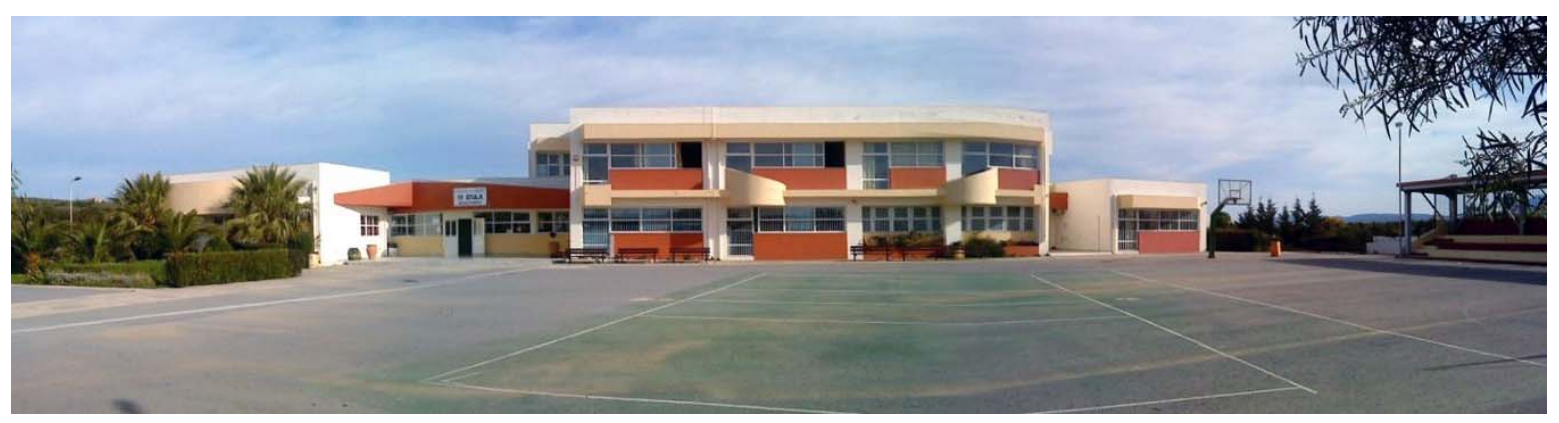

Figure 2. General view of the examined school building.

The annual energy sources recorded consumptions, based on the corresponding statements and invoices from the providers, before the building's energy upgrade were:

- electricity: $23,351 \mathrm{kWh}$ for indoor and outdoor spaces lighting and for offices and laboratories devices - diesel oil: $4500 \mathrm{lt}$, exclusively for the indoor space heating.

The building was adequately insulated, following the Hellenic Directive on Buildings' Energy Performance, valid in 2011, given also the relatively mild winter and cool summer, typical features in Mediterranean climates. No passive measures were applied. The energy upgrade of the building was mainly based on:

- the replacement of the old, energy consuming bulbs with new ones with LED technology

- the introduction of roof fans for physical cooling at the end and the beginning of the academic season

- the replacement of the existing diesel oil heater with a new solar-combi system.

This article will present in detail the introduced solar-combi system.

\subsection{Climate Conditions-R.E.S. Potential}

The climate at the location of the examined school building is typical Mediterranean. It is characterized by mild winters, with temperatures from 5 to $17^{\circ} \mathrm{C}$, and relatively cool summers with temperatures rarely higher than $30-32{ }^{\circ} \mathrm{C}$ and relative humidity below $75 \%$ during summer, due to the prevailing local north-west winds.

The incident solar radiation on the horizontal surface is presented in Figure 3, measured by a local meteorological station installed by the Hellenic National Meteorological Service (HNMS) [40], in a location roughly $15 \mathrm{~km}$ away from the building' location (coordinates $35^{\circ} 12^{\prime} 30^{\prime \prime} \mathrm{N}, 25^{\circ} 20^{\prime} 20^{\prime \prime} \mathrm{E}$ ). In Figure 3 is shown that the solar radiation can exceed $900 \mathrm{~W} / \mathrm{m}^{2}$ during summer, with a yearly global irradiation at $1857 \mathrm{kWh} / \mathrm{m}^{2}$. During winter it normally reaches values above $500 \mathrm{~W} / \mathrm{m}^{2}$.

In Figure 4 the annual time series of the wind velocity is presented, as measured by the same meteorological station. The annual average wind velocity is measured at $3.58 \mathrm{~m} / \mathrm{s}$, while the Weibull parameters are calculated at $\mathrm{C}=3.99 \mathrm{~m} / \mathrm{s}$ and $\mathrm{k}=1.42$. The above features indicate the existence of relatively mild wind conditions in the examined location. This annual wind velocity time series will be employed in this work for the calculation of:

- the thermal losses rate from the solar collectors

- the heating and cooling loads of the indoor space. 


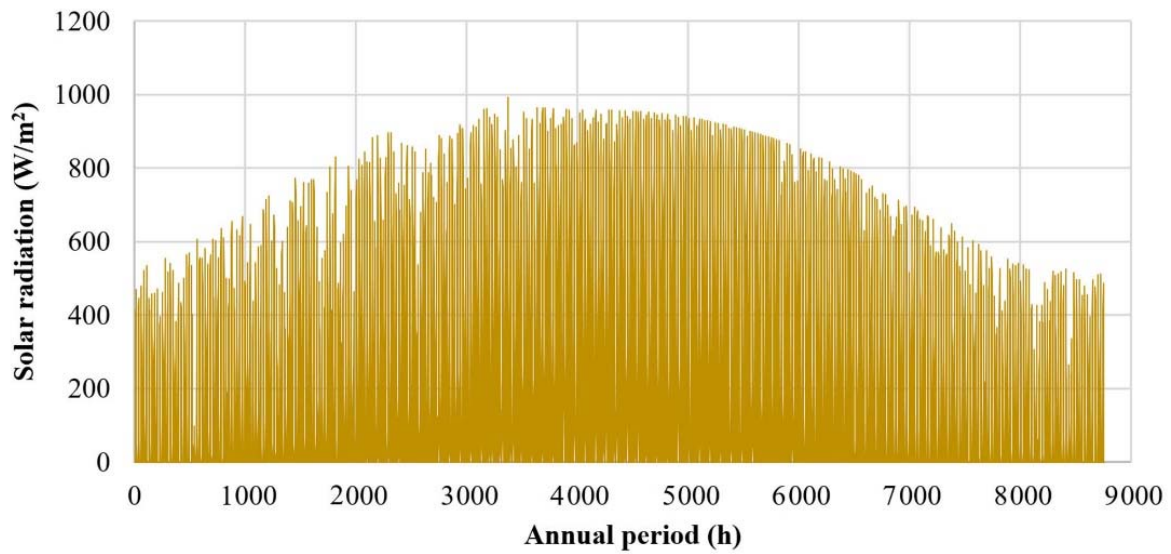

Figure 3. The annual time series of the available incident solar radiation on horizontal plane at the town of Arkalochori.

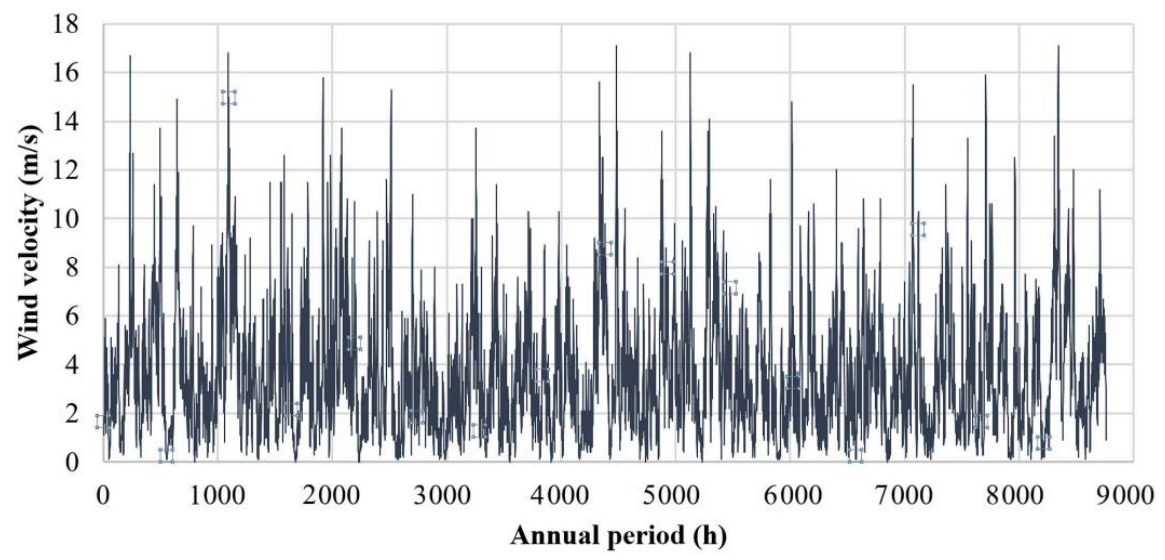

Figure 4. The annual wind velocity time series as measured by the meteorological station of the HNMS.

In Figure 5 the annual time series of the ambient temperature is presented, as measured by the above mentioned meteorological mast. The annual temperature and solar radiation time series will be employed in this work for the calculation of:

- the thermal power production from the introduced solar collectors

- the heating and cooling loads of the indoor space.

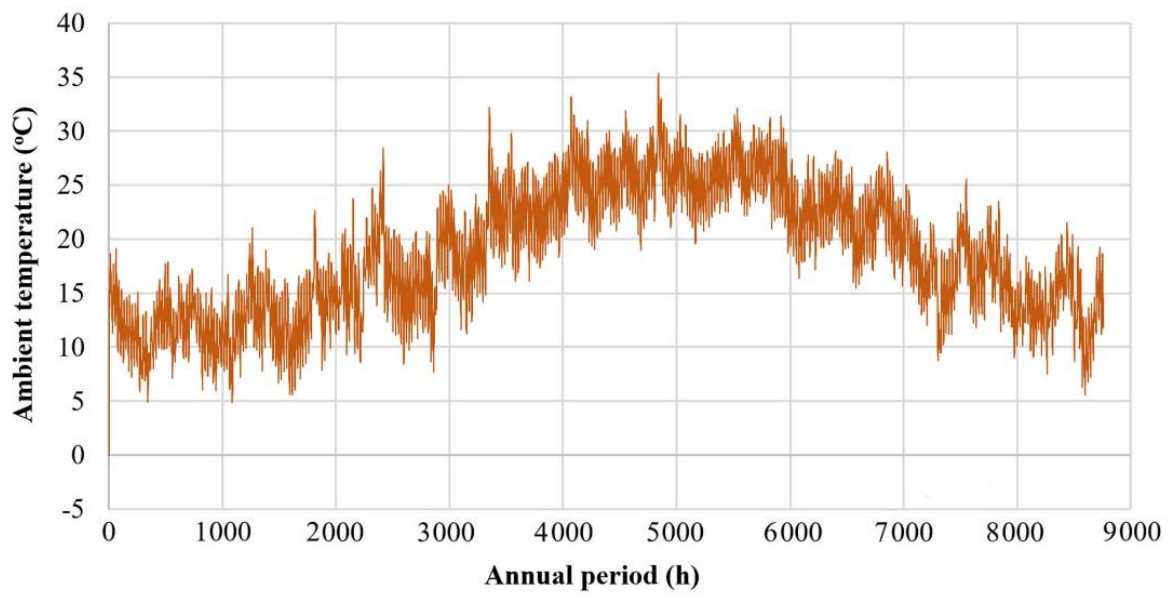

Figure 5. The annual ambient temperature time series at the town of Arkalochori. 


\subsection{Heating and Cooling Loads Calculation}

The building is extended on three floors (basement, ground and first floor). The covered area per floor and the determination of the thermal zones are presented in Table 1. Thermal zone 1 includes all the conditioned indoor space: classrooms, teachers' offices, laboratories, the events' hall and the toilets. Thermal zone 2 includes all the non-conditioned spaces in the building: escalators, repositories and boiler-machinery room. The constructive features of the building's envelope with their U-factors are presented in Table 2. The solar gain factor of the transparent surfaces is set at 0.77 .

Table 1. Covered areas and volumes of the conditioned and non-conditioned indoor space in the examined school building.

\begin{tabular}{ccccc}
\hline \multirow{2}{*}{ Floor } & \multicolumn{2}{c}{ Thermal Zone 1 (Conditioned Spaces) } & \multicolumn{2}{c}{ Thermal Zone 2 (Non-Conditioned Spaces) } \\
\cline { 2 - 5 } & Area $\left(\mathbf{m}^{\mathbf{2}}\right)$ & Volume $\left.\mathbf{( m}^{\mathbf{3}}\right)$ & Area $\left.\mathbf{( m}^{\mathbf{2}}\right)$ & Volume $\left(\mathbf{m}^{\mathbf{3}}\right)$ \\
\hline Basement & 31 & 108 & 368 & 1282 \\
Ground floor & 633 & 2216 & 347 & 1215 \\
First floor & 382 & 1337 & 133 & 471 \\
Total & 1046 & 3661 & 848 & 2968 \\
\hline
\end{tabular}

Table 2. Constructive features and U-factors of the building's envelope.

\begin{tabular}{|c|c|c|}
\hline Constructive Element & Description & U-Factor $\left(\mathrm{W} / \mathrm{m}^{2} \mathrm{~K}\right)$ \\
\hline Basement ground & $\begin{array}{l}\text { marble-lime plaster-insulation layer-water sealing } \\
\text { sheet-reinforced concrete plate }\end{array}$ & 0.985 \\
\hline Floors' ground & $\begin{array}{l}\text { marble-lime plaster-reinforced concrete plate-plaster-paint } \\
\text { coating }\end{array}$ & 2.985 \\
\hline Roof & $\begin{array}{c}\text { concrete plates-lime plaster-elastic asphalted } \\
\text { cardboard-insulation layer-reinforced concrete } \\
\text { plate-plaster-paint coating }\end{array}$ & 1.050 \\
\hline Vertical external walls & $\begin{array}{l}\text { paint coating-plaster-bricks-expanded } \\
\text { polystyrene-bricks-plaster-paint coating }\end{array}$ & 1.055 \\
\hline Internal vertical walls & paint coating-plaster-bricks-plaster-paint coating & 2.125 \\
\hline Windows-Doors & $\begin{array}{l}\text { aluminum frame, with no thermal brake, double } 4 \mathrm{~mm} \text { glazing } \\
\text { with } 6 \mathrm{~mm} \text { gap, no reflective coating }\end{array}$ & 2.70 \\
\hline
\end{tabular}

The calculation of the heating and cooling loads is based on the essential relevant methodology [41] and was executed with TRNSYS. The building's simulation model and the logical diagram introduced in the software application are presented in Figure 6.
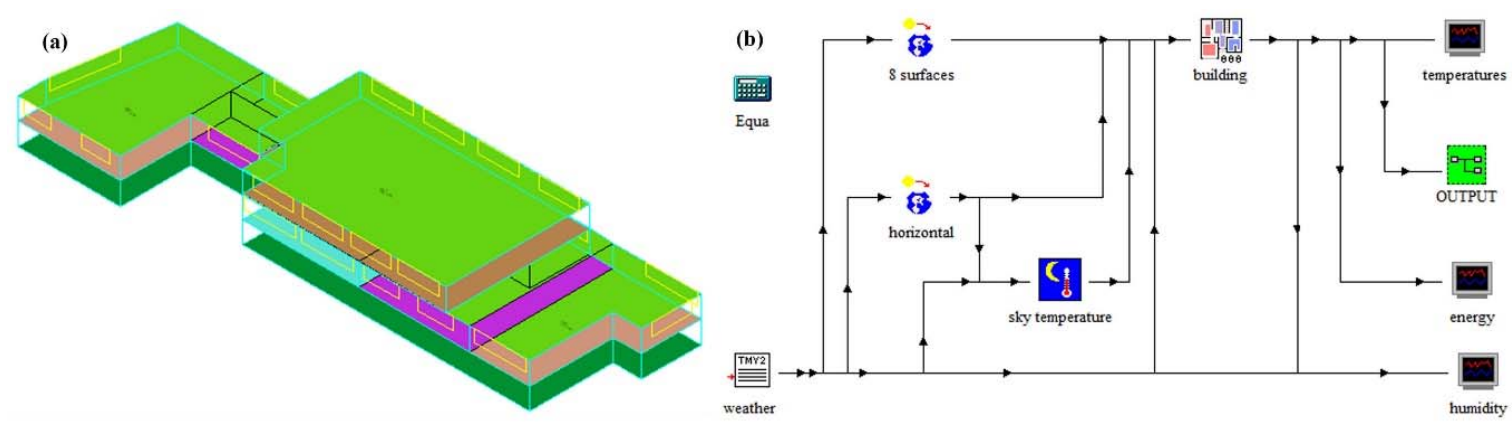

Figure 6. Building's computational simulation model (a) and calculation logical diagram (b) introduced in TRNSYS for the heating and cooling loads calculation.

The involved thermophysical parameters are introduced either from the Hellenic Directive on Buildings' Energy Performance [42] or the ASHRAE Fundamentals [43]. Specifically:

- the thermal transition coefficients $h_{i}$ and $h_{o}$ for the indoor or the ambient space respectively to the envelope were set: 
- $\quad h_{i}=10 \mathrm{~W} / \mathrm{m}^{2} \mathrm{~K}$ and $\mathrm{h}_{\mathrm{o}}=25 \mathrm{~W} / \mathrm{m}^{2} \mathrm{~K}$ for air flow over horizontal surfaces and for an average wind speed of $5 \mathrm{~m} / \mathrm{s}$

- $\quad h_{i}=7.7 \mathrm{~W} / \mathrm{m}^{2} \mathrm{~K}$ and $\mathrm{h}_{\mathrm{o}}=25 \mathrm{~W} / \mathrm{m}^{2} \mathrm{~K}$ for air flow next to vertical surfaces and for an average wind speed of $5 \mathrm{~m} / \mathrm{s}$

- the natural ventilation coefficient from the openings' frames is set equal to 1

- thermal comfort conditions: temperature $22{ }^{\circ} \mathrm{C}$ in winter and $26{ }^{\circ} \mathrm{C}$ in summer, relative humidity $50 \%$

- ventilation requirements: $26 \mathrm{~m}^{3} / \mathrm{h} \&$ user [42]

- internal heat gains from humans, devices etc., as defined in the relevant Hellenic Directive on Buildings' Energy Performance [42]

- the daily operation schedule and the average users number were provided by the building's Management: Monday-Friday: 8:00-17:00, from the 10th of September to the 15th of June; from the 16th of June to the 10th of September school remains closed (only the offices operate for the remaining days of September and June).

Table 3. Monthly analysis of the heating and cooling loads of the examined building.

\begin{tabular}{|c|c|c|c|c|}
\hline \multirow{2}{*}{ Months } & \multicolumn{2}{|c|}{ Monthly Total Thermal Loads (kWh) } & \multicolumn{2}{|c|}{ Monthly Peak Loads (kW) } \\
\hline & Heating & Cooling & Heating & Cooling \\
\hline January & 8243 & 23 & 240.94 & 1.66 \\
\hline February & 7026 & 60 & 219.70 & 2.65 \\
\hline March & 5946 & 160 & 198.86 & 3.40 \\
\hline April & 841 & 409 & 128.36 & 60.14 \\
\hline May & 0 & 1546 & 80.08 & 80.98 \\
\hline June & 0 & 1820 & 5.93 & 76.64 \\
\hline July & 0 & 0 & 0.00 & 0.00 \\
\hline August & 0 & 0 & 0.00 & 0.00 \\
\hline September & 0 & 1656 & 3.51 & 80.48 \\
\hline October & 422 & 622 & 81.06 & 61.71 \\
\hline November & 3316 & 6 & 158.11 & 0.95 \\
\hline December & 6561 & 11 & 214.88 & 1.29 \\
\hline Totals $/ \max$ & 32,356 & 6314 & 240.94 & 80.98 \\
\hline Total heating and cooling & \multicolumn{2}{|c|}{35,670} & - & - \\
\hline Totals specific & 30.93 & 6.04 & - & - \\
\hline
\end{tabular}

In Table 3 the monthly summarized results from the heating and cooling loads calculation are presented. The results presented in this table can be summarized as follows:

- The annual final thermal energy consumed for heating and cooling is calculated at $32.4 \mathrm{MWh}$ and 6.3 MWh, respectively.

- The total final specific thermal energy consumption per unit of conditioned space covered area $\left(1046 \mathrm{~m}^{2}\right)$ is calculated equal to $30.93 \mathrm{kWh} / \mathrm{m}^{2}$ for heating and $6.04 \mathrm{kWh} / \mathrm{m}^{2}$ for cooling.

- The total final thermal energy specific consumption for the conditioning of the indoor space is calculated at $36.97 \mathrm{kWh} / \mathrm{m}^{2}$.

By assuming the following efficiencies of the central heating system:

- diesel oil heater: 0.80

- $\quad$ heating distribution hydraulic network: 0.88

- $\quad$ heating radiators: 0.92

and the diesel oil lowest calorific value equal to $10.25 \mathrm{kWh} / \mathrm{lt}$ [42], it is calculated that the annual oil consumption for the $100 \%$ heating loads coverage of the school building should be: 
By comparing the above result with the recorded annual diesel oil consumption (4500 lt), the accuracy and the adequacy of the computational simulation process applied for the calculation of the building's heating loads is verified.

By introducing the diesel oil procurement price in Crete at $0.95 € / 1 \mathrm{t}$, the annual diesel oil procurement cost for the total annual coverage of the building's heating loads is calculated at $4630 €$. The thermal power production annual cost, accounting:

- the above calculated diesel oil procurement cost

- an annual maintenance cost of $200 €$

- the annual amortization of the invested capital assumed at $5000 €$ over a period of 20 years

is calculated at $5080 €$. The corresponding levelized production cost is calculated at $0.1570 € / \mathrm{kWh}_{\mathrm{th}}$. In Figure 7 the annual variation of the school building's heating and cooling loads is depicted.

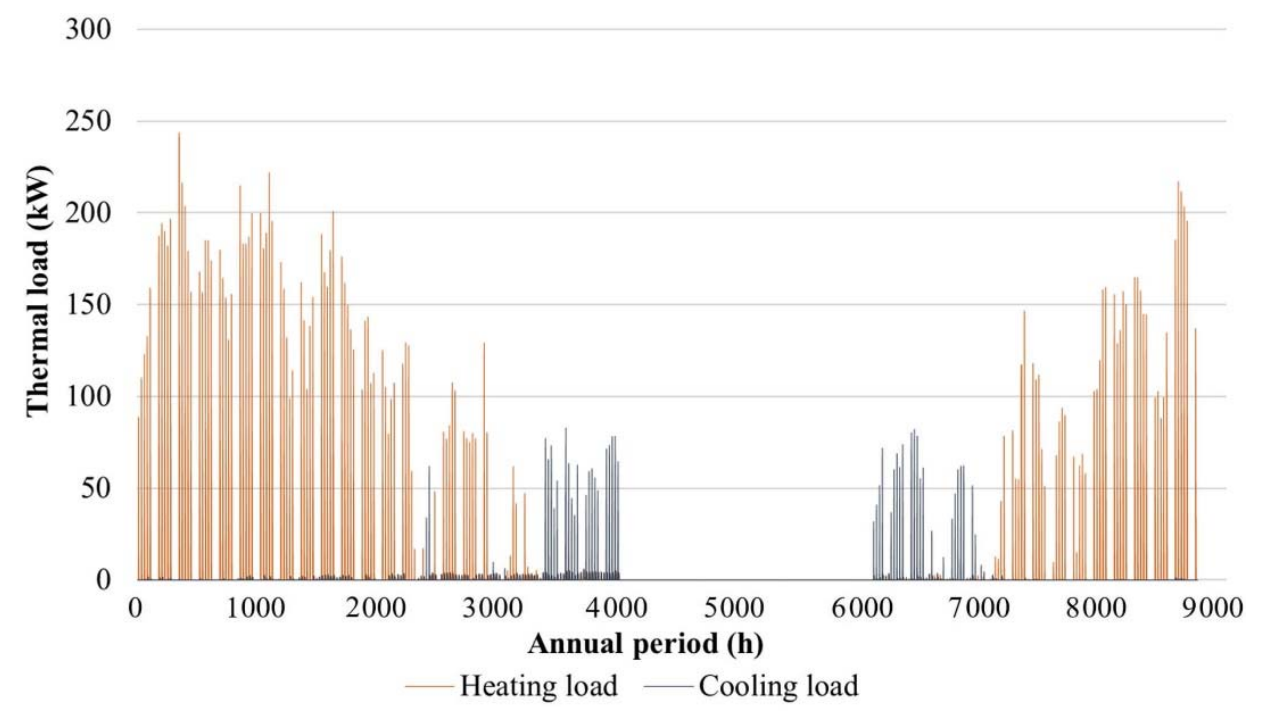

Figure 7. Annual time series of the heating and cooling loads of the examined school building.

In Figure $8 \mathrm{a}, \mathrm{b}$ the heating loads fluctuation is depicted for the first two weeks of January and December respectively. In these figures it is seen that the heating loads are maximized with the beginning of the new working day, and then they gradually drop.

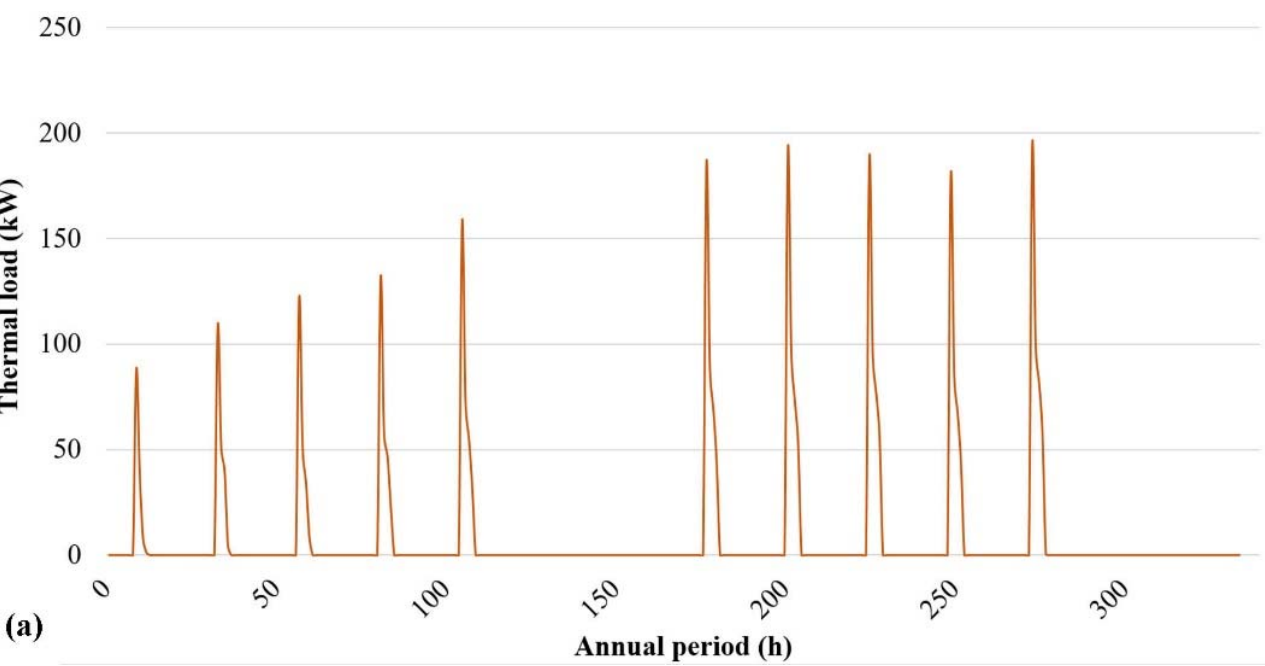

Figure 8. Cont. 


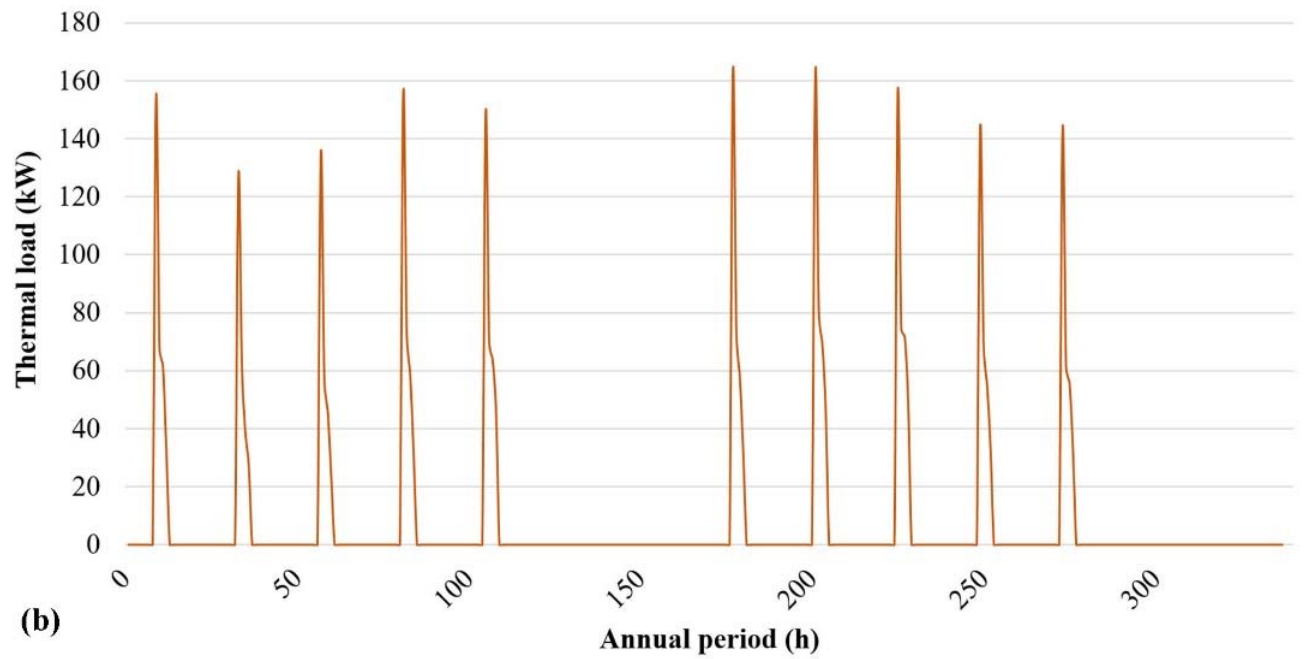

Figure 8. Heating loads fluctuation for the first two weeks of (a) January and (b) December.

This means that, practically, during the nights or the weekends, any potentially positive effect of the building's thermal inertia is lost. Additionally, all the uncovered heating loads during the inoperative periods are cumulated for the beginning of the next working day.

\section{The Introduced Solar-Combi System}

\subsection{Scope}

Within the framework of the energy upgrade of the examined school building, a solar-combi system was proposed and studied aiming at the $100 \%$ coverage of the indoor space heating loads. The solar-combi system was selected given the following very specific reasons:

- The high available solar radiation in the under consideration area and the availability of potentially abundant biomass fuel, mainly coming from the olive trees pruning.

- Greece holds the third place in Europe regarding the installation of solar collectors per capita, so far mainly for hot water production. This achievement has already enabled the development of a considerable domestic industry on the manufacturing of solar collectors. Additionally, the exploitation of the annually available huge amounts of pruning coming from the olive trees for the production of local biomass pellets can trigger the development of another significant local industry sector, contributing to the enforcement of the local economy.

- The installation of a solar-combi system in a school building can act as a pilot project, fostering the transition from the oil-based heating systems to the solar heating systems.

- This system can guarantee $100 \%$ coverage of the building's heating needs with locally available Renewable Energy Sources (solar radiation and biomass), substituting the currently imported oil and contributing, thus, further to the support of the local economy.

A new operation algorithm is developed for the examined solar-combi system. The objective of the introduced operation algorithm is the realization of the above scope (100\% coverage of the indoor space heating loads) by maximizing the thermal power production by the solar collectors, reducing respectively the biomass consumption, while, at the same time, obtaining the minimum possible thermal energy annually levelized production cost. This cost will be approached with the following relationship:

$$
\text { L.C. }=\frac{\frac{\text { I.C. }}{N}+\frac{\sum_{n=1}^{N} \frac{\text { A.O.C. }}{(1+\mathrm{i})^{\mathrm{n}}}}{\mathrm{N}}}{\mathrm{E}_{\mathrm{th}}}
$$

where: 
L.C.: the annually average, thermal energy production levelized cost (in $€ / \mathrm{kWh}_{\mathrm{th}}$ )

I.C.: the initial cost (set-up cost) of the solar-combi system (in $€$ )

A.O.C.: the total annual operation and maintenance cost (in $€ /$ year)

i: the discount rate, assumed equal to $3 \%$

$\mathrm{N}$ : the total life period of the solar-combi system, assumed equal to 20 years

$\mathrm{n}$ : the number of the current year of the system's operation

$\mathrm{E}_{\mathrm{th}}$ : the annual thermal energy production of the solar-combi system $\left(\mathrm{kWh}_{\mathrm{th}}\right)$.

Given the request for 100\% annual coverage of the building's indoor space heating, the annual thermal energy production $E_{\text {th }}$ is equal to the annual thermal energy demand, calculated in Table 3 equal to $32,356 \mathrm{kWh}_{\text {th }}$.

\subsection{Operation Algorithm-Realization}

The general layout of the solar-combi system is presented in Figure 9. It consists of the solar collectors' field, two, three or four thermal storage water tanks of $5000 \mathrm{lt}$ volume capacity each and a back-up biomass heater. The number of the thermal storage tanks will be determined by the optimized dimensioning, which will be executed on the basis of the minimization of the levelized cost.

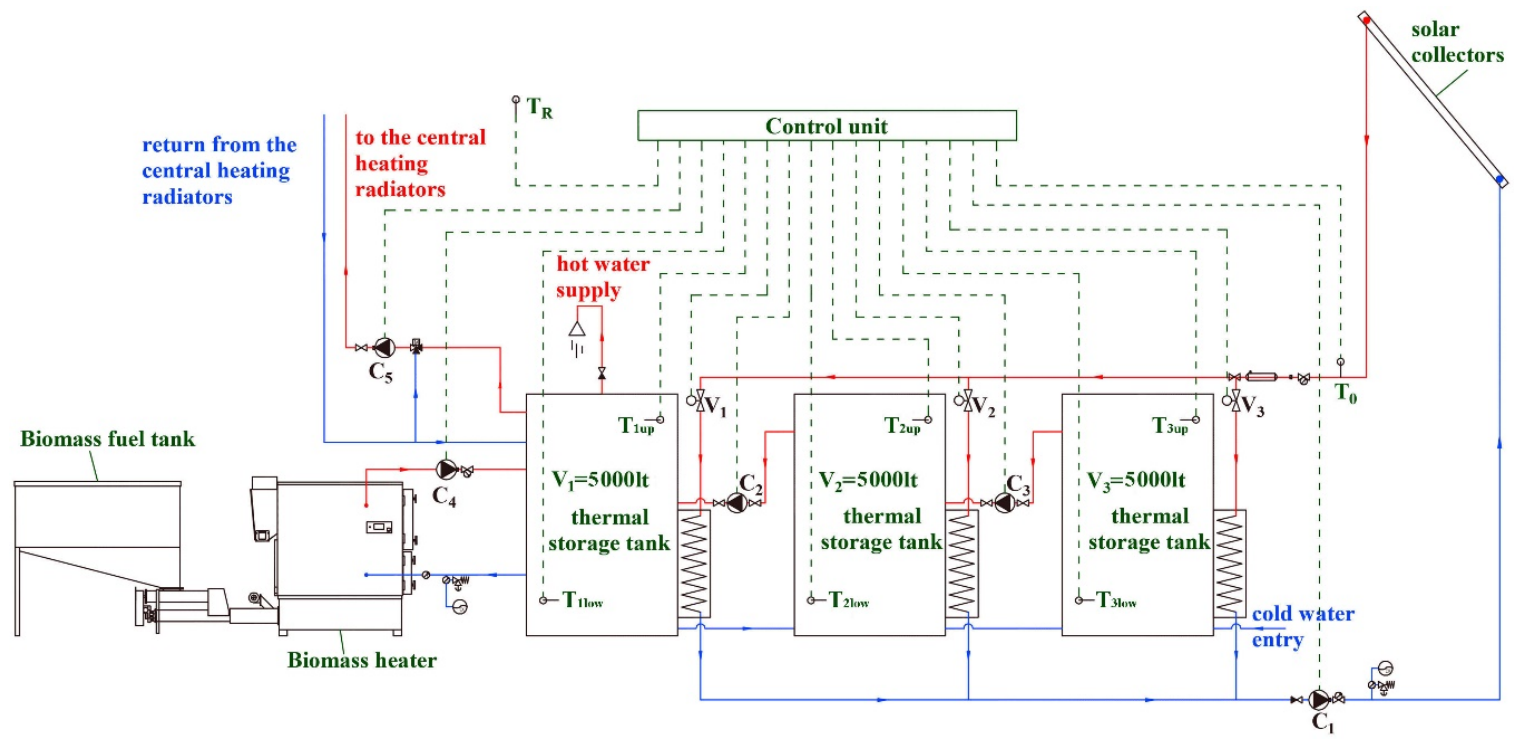

Figure 9. Graphical representation of the connectivity layout and the realization of the operation algorithm of the proposed system.

The biomass heater will be compatible with the relevant national and international standards (e.g., the ELOT 303-5 Greek national standard). The burner should be able to burn any kind of solid biomass fuel, such as pellets, olive kernels or any kind of small size solid biomass (e.g., nutshells). The overall efficiency of the biomass heater should be at the range of $85 \%$. To facilitate the automatic operation of the whole system, the biomass heater should be equipped with all the technical specifications provided by the state of the art level of the relevant technology. Specifically:

- The biomass fuel will be automatically fed from the indoor fuel tank into the burner through a duct, operated by a conveyor, run by an electric motor.

- The burner will be equipped with an automatic ignition system with a blower, managed directly by the central control unit of the solar-combi system.

- The removal of the combustion residue should be facilitated with a specially designed system. Specifically, the residue will be collected to a removable bottom drawer. By removing this drawer, all the collected residue will be removed. 
- To minimize any potential environmental impacts, the burner's chimney will be equipped with a cyclonic filter.

The type and the size of the introduced thermal tanks will support stratification thermal energy storage. This means that thermal energy will be stored inside the water thermal tanks maintaining a gradual increase of the water temperature from the tanks' bottom to the top, as illustrated in Figure 10.

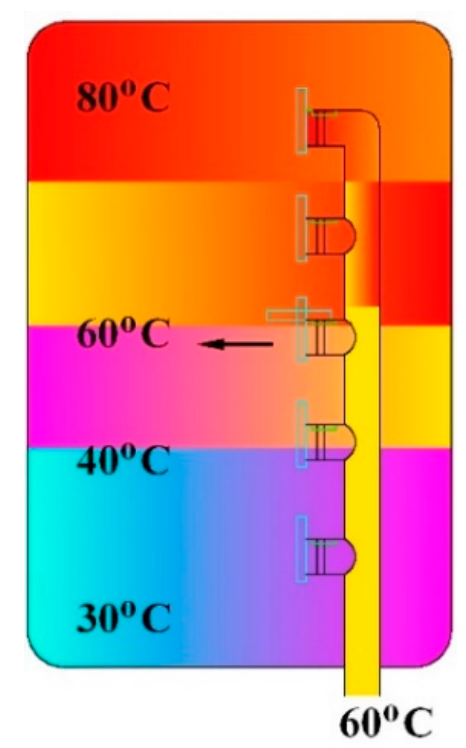

Figure 10. Stratification thermal energy storage in a water tank.

Stratification thermal storage is automatically achieved, through the transition of the warmer and lighter masses of the storage medium towards the upper layers of the thermal tank with physical flow, namely without any mechanical support. The required thermal power is always provided for the demand from the upper layer of the thermal tank, in order to ensure that thermal power will be distributed with the maximum achieved temperature. At the same time, the available for storage thermal power is provided for the thermal tank through a heat exchanger located close to the tank's bottom, in order to maximize the probability that the working fluid's temperature in the solar collectors' primary loop will be higher than the lowest temperatures existing in the thermal tank's low layers. In this way, the final storage of the initially available thermal power from the solar collectors' field is maximized.

The system's operation is automatically managed by a central control unit and facilitated through a number of thermometers, motor-vanes and circulators. Specifically, as seen in Figure 9, the control unit:

- $\quad$ receives signals from the thermometers $T_{R}, T_{0}, T_{1 \text { low }}, T_{1 \text { up }}, T_{2 l o w}, T_{2 u p}, T_{3 l o w}, T_{3 u p}$, from the lower and the upper layers of the thermal storage tanks, where $T_{R}$ the temperature signal of the indoor space thermostat (or thermostats, in case more than one thermal zones of conditioned space with different required thermal comfort conditions are introduced)

- $\quad$ sends orders to the motor-vanes $V_{1}, V_{2}$ and $V_{3}$ and to the circulators $C_{1}, C_{2}, C_{3}, C_{4}$ and $C_{5}$.

The operation concept of the solar-combi system focuses on:

- the maintenance of the temperature inside the thermal tank 1 as high as possible, in order to minimize the biomass heater operation

- the maximization of the thermal energy storage from the solar collectors, even in cases this is available in relatively low temperatures.

The above objectives are simply approached by maintaining the highest water temperatures in thermal tank 1 and gradually decreasing temperatures in thermal tanks 2 and 3. In other words, 
the storage temperature in the available thermal storage tanks should be gradually kept lower from the tank 1 to the tank 3 , in order to ensure that there will always be a storage tank with the minimum possible storage temperature, to maximize solar energy exploitation even in the early morning hours, when the working medium's temperature in the primary solar collectors loop is still relatively low. At the same time, the conservation of the maximum possible temperature in the thermal tank 1 will enable the minimization of the biomass heater operation. This storage tank will be the "load tank", since the central heating distribution network will be supplied exclusively from this tank. Additionally, as shown in Figure 9, the biomass heater will be also exclusively connected to this load tank.

The automatic operation of the combi-solar system under the above mentioned requirements is realized with the central control unit, the five circulating pumps, the three motorized valves, the eight temperature sensors installed as depicted in Figure 9 and the overall system's layout presented in the same figure. The above tasks are automatically realized with orders and the corresponding different operation modes presented in the lines below:

- if $\mathrm{T}_{\mathrm{R}}<\mathrm{T}_{\mathrm{TC}}$ then $\mathrm{C}_{5}=\mathrm{ON}$

- if $\mathrm{T}_{0}>\mathrm{T}_{1 \text { low }}$ then: $\mathrm{C}_{1}=\mathrm{ON}, \mathrm{V}_{1}=$ open, $\mathrm{V}_{2}=$ close, $\mathrm{V}_{3}=$ close

- if $\mathrm{T}_{0}<\mathrm{T}_{1 \text { low }}$ and $\mathrm{T}_{0}>\mathrm{T}_{2 \text { low }}$ then: $\mathrm{C}_{1}=\mathrm{ON}, \mathrm{V}_{1}=$ close, $\mathrm{V}_{2}=$ open, $\mathrm{V}_{3}=$ close

- if $\mathrm{T}_{0}<\mathrm{T}_{1 \text { low }}$ and $\mathrm{T}_{0}<\mathrm{T}_{2 \text { low }}$ and $\mathrm{T}_{0}>\mathrm{T}_{3 \text { low }}$ then: $\mathrm{C}_{1}=\mathrm{OFF}, \mathrm{V}_{1}=$ close, $\mathrm{V}_{2}=$ close, $\mathrm{V}_{3}=$ open

- if $\mathrm{T}_{2 \text { up }}>\mathrm{T}_{1 \text { low }}$ then: $\mathrm{C}_{2}=\mathrm{ON}$

- if $\mathrm{T}_{3 \text { up }}>\mathrm{T}_{2 \text { low }}$ then: $\mathrm{C}_{3}=\mathrm{ON}$

- if $\mathrm{T}_{1 \text { up }}<70{ }^{\circ} \mathrm{C}$ then: $\mathrm{C}_{4}=\mathrm{ON}$.

where $\mathrm{T}_{\mathrm{TC}}=22{ }^{\circ} \mathrm{C}$ (see Section 2.3) the required thermal conditions temperature of the indoor conditioned space. The operation temperature range of the heating distribution network was set at $70-55{ }^{\circ} \mathrm{C}$ temperature. The supply temperature for the heating distribution network was set at this relatively low value to foster the penetration of the thermal power penetration in the system from the solar collectors and approach higher achieved performance efficiencies of the solar collectors.

\subsection{Simulation Methodology}

The dimensioning procedure was based on the arithmetic simulation of the annual operation of the combi-solar system, based on the fundamental theory of solar collectors and thermal energy storage. The full mathematical background of the executed simulation process is analytically presented in [44]. The solar collectors' performance was simulated with the TRNSYS software application and the annual thermal power production time series was developed respectively. The employed TRNSYS model is presented in Figure 11. The simulation was executed for 5 different scenarios regarding the size of the solar collectors' field, with $36,40,44,48$ and 52 solar collectors involved in each one of them, with an effective collector's surface of $2.30 \mathrm{~m}^{2}$. The solar collectors for each different scenarios were divided in parallel groups of 4 collectors connected in series, as presented in Figure 12.

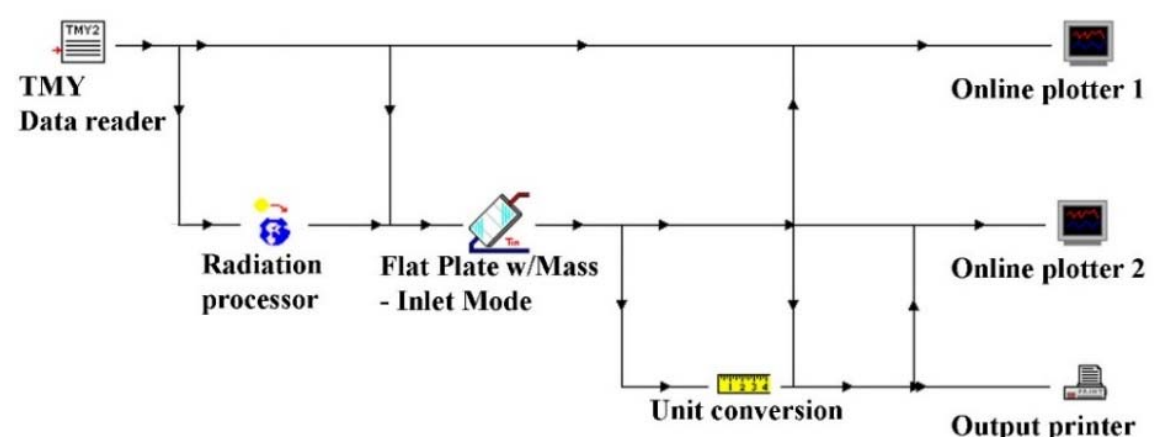

Figure 11. Calculation logical diagram introduced in TRNSYS for the simulation of the solar collectors operation. 


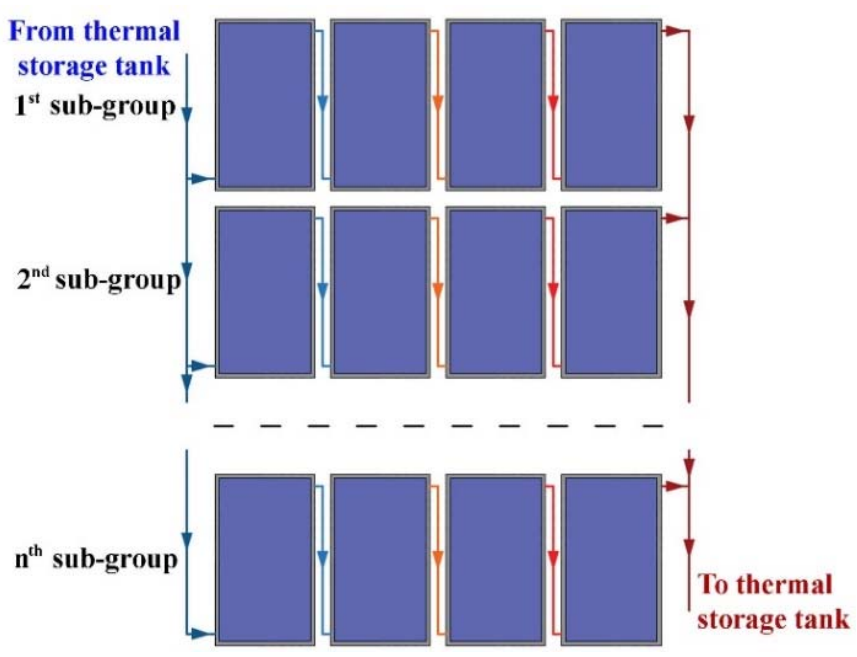

Figure 12. Connection layout of the solar collectors' field.

The TRNSYS simulation model was also utilized for the determination of the optimum installation angle of the solar collectors versus the horizontal plane. This was executed aiming at the maximisation of the thermal energy production during the winter period (from the 1st of November to the 31st of March) and for the geographical latitude of the under consideration location $\left(35^{\circ}\right)$. By executing similar simulations of the solar collectors' performance under alternative installation angles with an increment step of $5^{\circ}$, it was concluded that the optimum installation angle is $45^{\circ}$. Obviously the solar collectors are oriented to the south (collectors' surface azimuth angle equal to $0^{\circ}$ ). For this optimum installation angle and orientation, the annual variation of the total incident solar radiation (direct, diffused and reflected) per unit of solar collectors' surface (in $\mathrm{W} / \mathrm{m}^{2}$ ) is depicted in Figure 13. The simulation process is based on the following essential steps:

- The simulation is executed on hourly, average calculation time steps.

- For every hourly calculation step, the thermal power production $\mathrm{P}_{\mathrm{sc}}$ from the solar collectors' field is provided from the corresponding time series developed with TRNSYS.

- If $P_{t d}$ is the thermal power demand, then the direct thermal power production penetration $P_{s p}$ from the solar collectors' field to the thermal power demand coverage is simply calculated as:

if $P_{t d} \geq P_{s c}$ then $P_{s p}=P_{s c}$

if $P_{t d}<P_{s c}$ then $P_{s p}=P_{t d}$.

- The thermal power storage $\mathrm{P}_{\text {sta }}$ from the solar collectors will in any case be:

$\mathrm{P}_{\text {sta }}=\mathrm{P}_{\mathrm{sc}}-\mathrm{P}_{\mathrm{sp}}$

- The remaining thermal power demand $\mathrm{P}_{\mathrm{tdr}}$, after the direst penetration from the solar collectors will be:

$\mathrm{P}_{\mathrm{tdr}}=\mathrm{P}_{\mathrm{td}}-\mathrm{P}_{\mathrm{sp}}$.

- The remaining thermal energy demand and the total thermal energy storage from the solar collectors are calculated for every $24-\mathrm{h}$ period, by integrating the corresponding $24-\mathrm{h}$ thermal power time series.

- For the current 24-h period, the thermal power demand coverage from the stored thermal energy from the previous 24 -h period is calculated. Any possible remaining stored power will be utilized for the next 24-h period (this mainly happens during the late autumn or the early spring period).

- Finally, any remaining thermal power demand, after the exploitation of the stored thermal power will be covered by the biomass heater. This thermal energy is also calculated on a 24-h basis. 
- Given the above approach, the dimensioning of the required thermal storage tank is imposed by the maximum required thermal energy storage from the solar collectors for a 24 -h period during the year.

- For each different dimensioning scenario, regarding the required thermal storage capacity and the solar collectors total number, the annual time series of mean hourly or daily values are calculated for the:

- $\quad$ initial thermal power production from the total solar collectors' field

- $\quad$ the solar collectors' direct thermal power penetration for the indoor space heating loads coverage

- $\quad$ the thermal power storage from the solar collectors

- $\quad$ the thermal power production from the biomass heater.

- Annual statistics for the thermal energy produced and stored from the solar collectors and the biomass heater are eventually calculated by integrating the above mentioned developed corresponding annual time series.

The results from the execution of the applied methodology are presented in the next section.

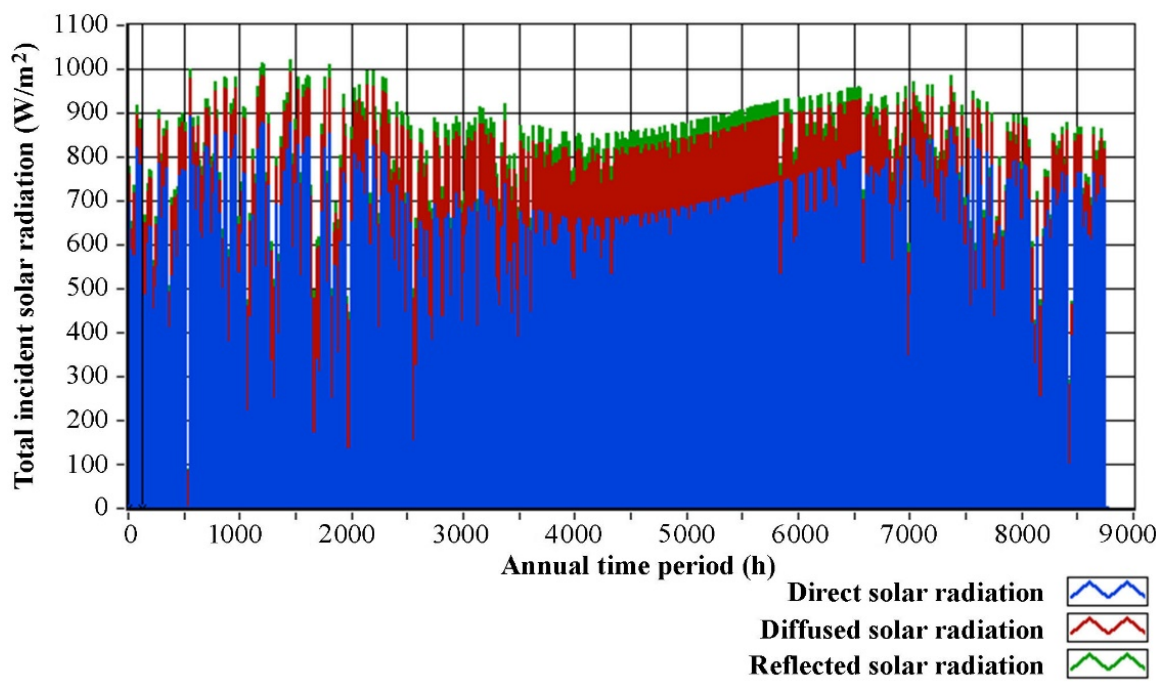

Figure 13. Annual variation of the total incident solar radiation for the installation angle of $45^{\circ}$ and for south orientation.

\subsection{Results}

The essential results from the annual simulation of the solar-combi system's operation regarding the annual energy production and storage are presented in Table 4.

Table 4. Annual thermal energy production and storage results.

\begin{tabular}{cccccc}
\hline Number of Solar Collectors & $\mathbf{3 6}$ & $\mathbf{4 0}$ & $\mathbf{4 4}$ & $\mathbf{4 8}$ & $\mathbf{5 2}$ \\
\hline Solar collectors total surface $\left(\mathrm{m}^{2}\right)$ & 82.8 & 92 & 101.2 & 110.4 & 119.6 \\
Solar collectors production from $15 / 10-15 / 4$ & 17,072 & 18,774 & 20,480 & 22,097 & 23,801 \\
Solar collectors direct thermal energy penetration & 4711 & 5093 & 5448 & 5803 & 6157 \\
Solar collectors thermal energy available for storage & 12,361 & 13,680 & 15,031 & 16,294 & 17,644 \\
Solar collectors thermal energy eventually stored & 7677 & 8354 & 9068 & 9721 & 10,292 \\
Biomass heat thermal energy production & 19,968 & 18,909 & 17,840 & 16,833 & 15,907 \\
Total thermal energy production & 32,356 & 32,356 & 32,356 & 32,356 & 32,356 \\
Required thermal storage capacity $(\mathrm{kWh}$ th) & 198.98 & 220.25 & 241.81 & 262.76 & 283.82 \\
Required water tanks capacity (kg) & 11,370 & 12,586 & 13,818 & 15,015 & 16,219 \\
Solar collectors' annual percentage coverage $(\%)$ & 38.29 & 41.56 & 44.86 & 47.98 & 50.84 \\
Solar collectors' thermal energy annual percentage surplus (\%) & 27.43 & 28.37 & 29.12 & 29.75 & 30.89 \\
\hline
\end{tabular}


By observing the results presented in Table 4, it is possible to proceed to the following remarks:

- The annual contribution of the solar collectors to the thermal energy demand coverage ranges from $38 \%$ to $50 \%$, for the different investigating scenarios, versus the total installed solar collectors' surface. The remaining thermal energy demand is covered with the biomass heater.

- Percentage $27-28 \%$ of the total thermal energy contribution from the solar collectors comes from direct penetration and the rest percentage comes from the utilization of the stored thermal energy.

- The annual thermal energy surplus from the solar collectors is relatively lowly restricted, namely from $27 \%$ to $30 \%$. This verifies the appropriate dimensioning of the required thermal storage tanks. On the other hand, this low annual thermal energy surplus is sensible and should be expected, given the fact that:

- the simulation refers to the winter period, during which the available solar radiation is relatively low

- $\quad$ at the same period, there is a considerable heating load of a school building with covered area of indoor conditioned spaces higher than $1000 \mathrm{~m}^{2}$, supposed to be covered by this particular solar collectors' field.

In Table 5, the results from the calculation of the thermal energy production levelized cost are presented. The following set-up costs and procurement prices have been adopted, based on commercial quotations from equipment manufacturers and suppliers:

- biomass heater and accessories procurement-installation cost: 30,150€

- solar collector with selective coating procurement cost: $220 €$

- water thermal storage tank of $5000 \mathrm{lt}$ capacity procurement cost: $10,000 €$

- remaining hydraulic and electronic equipment procurement and installation cost: $8000 €$

- biomass pellets procurement price (in Crete): $350 € / \mathrm{tn}$

- the annual average maintenance and operation cost is configured by the consumed biomass pellets procurement cost and the biomass heater annual maintenance cost, set, on average, equal to $200 €$.

Table 5. Calculation of the thermal energy production annual average levelized cost.

\begin{tabular}{|c|c|c|c|c|c|c|}
\hline \multirow{2}{*}{ Cost Component } & \multicolumn{6}{|c|}{$\begin{array}{l}\text { Investigating Scenario (Number of Solar } \\
\text { Collectors/Thermal Tanks) }\end{array}$} \\
\hline & $36 / 3$ & $40 / 3$ & $44 / 3$ & $48 / 3$ & $52 / 4$ & $52 / 3$ \\
\hline Biomass heater cost $(€)$ & 30,150 & 30,150 & 30,150 & 30,150 & 30,150 & 30,150 \\
\hline Solar collectors cost $(€)$ & 7920 & 8800 & 9680 & 10,560 & 11,440 & 11,440 \\
\hline Thermal storage tanks cost $(€)$ & 30,000 & 30,000 & 30,000 & 30,000 & 40,000 & 30,000 \\
\hline Rest equipment cost $(€)$ & 8000 & 8000 & 8000 & 8000 & 8000 & 8000 \\
\hline Total set-up cost $(€)$ & 76,070 & 76,950 & 77,830 & 78,710 & 89,590 & 79,590 \\
\hline Biomass pellets annual consumption (tn) & 3.840 & 3.636 & 3.431 & 3.237 & 3.059 & 3.096 \\
\hline Average annual maintenance and operation cost $(€)$ & 1200 & 1147 & 1093 & 1043 & 996 & 1006 \\
\hline Thermal energy production levelized cost $\left(€ / \mathrm{kWh}_{\mathrm{th}}\right)$ & 0.1546 & 0.1544 & 0.1541 & 0.1539 & 0.1692 & 0.1541 \\
\hline
\end{tabular}

Finally, the lowest calorific value of the biomass pellets was assumed equal to $5.2 \mathrm{kWh} / \mathrm{kg}$. From the results presented in Table 5, it is concluded that the optimum size for the introduced solar-combi system, with regard to the minimization of the thermal energy production levelized cost, is configured with the installation of 48 solar collector with selective coating and $2.3 \mathrm{~m}^{2}$ of effective surface and three thermal storage tanks of $5000 \mathrm{~L}$ water storage capacity each. The minimum achieved levelized cost for thermal energy production, based on the above mentioned assumptions and prices, is calculated at $0.1539 € / \mathrm{kWh}_{\mathrm{th}}$. For the next investigating scenario, with the installation of 52 solar collectors, one additional thermal storage tank is required, raising considerably the total set-up cost and the corresponding production levelized cost. Nevertheless, it should be noticed that even if the number of the thermal storage tanks is theoretically kept at 3, instead of 4 , for the dimensioning 
scenario of 52 solar collectors, the arisen production levelized cost is calculated at $0.1541 € / \mathrm{kWh}_{\text {th }}$, namely higher than the corresponding figure of the scenario with 48 collectors, which still remains the optimum one.

In Figure 14, power production synthesis curves are presented for (a) the period from the 1st of January to the 15th of April and (b) the period from the 15th of October to the 31st of December. Interesting conclusions are derived from these figures:

- After the weekends, the stored thermal energy in the thermal storage tanks undertakes most of the thermal power demand for the first days of the new week.

- While approaching the last days of March or during the last days of October, the thermal power direct penetration of the solar collectors and the contribution of the thermal storage tanks undertakes all the heating loads. The biomass heater contribution during these periods is negligible.

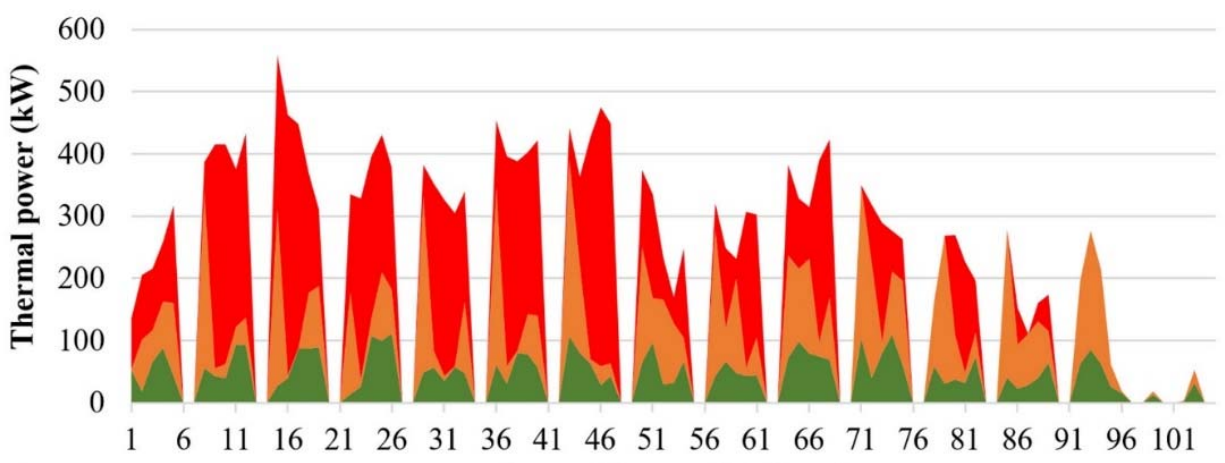

(a) Annual time period (days)

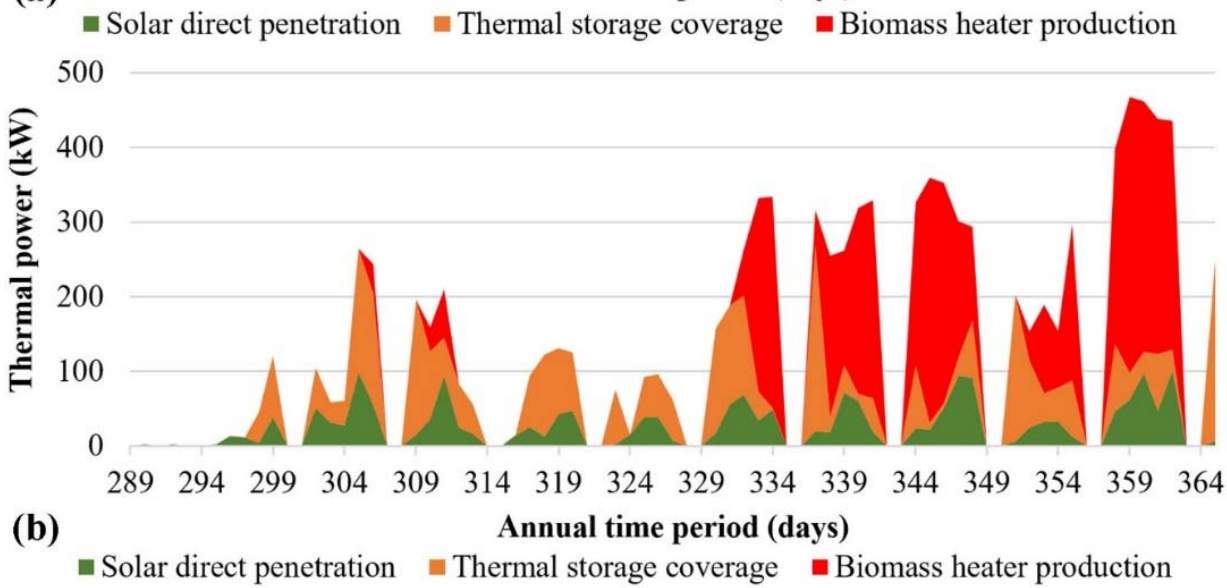

Figure 14. Thermal power production synthesis from the solar-combi system components for (a) the period from $1 / 1$ to $15 / 4$ and (b) the period from $15 / 10$ to $31 / 12$.

Given the annual operation and maintenance cost of the existing oil-based central heating system (5080 $€$, see Section 2.3) and the corresponding figure of the optimized proposed solar-combi system (1043€, Table 5) the net annual economic benefit from the solar-combi system introduction and the elimination of the diesel oil consumption equals to $4037 €$. Given also the total set-up cost of optimized solar-combi system $(78,710 €$, Table 5), its payback period is calculated at 19.50 years. This figure is certainly quite high, yet, the following facts should be taken into account:

- The specific school building has a limited operation period for roughly 8-10 h per day and for five days per week. Additionally, the existing thermal energy needs in the building refer only to the indoor space heating loads, appeared only for six months per year. 
- No other thermal energy needs, apart from the indoor space heating, are present due to the lack of additional facilities, e.g., gyms accompanied with changing rooms and showers, swimming pools, dormitories etc.

- The economic feasibility of the same system in another type of building at the same geographical location (e.g., a residence or a sports hall with extensive hot water needs) is expected much higher. In this case, the annual average thermal energy production cost should be also expected much lower than the calculated figures in this article.

- However, the specific project has a strong demonstrative aspect, given the daily use of the school building from students, namely from people with their educational background still under cultivation. The proposed system, along with the rest energy saving measures proposed in the frame of the building's energy performance upgrade, aim to contribute, apart from the obvious energy saving target, to the cultivation of the rational energy use culture for the building's users and visitors.

- Finally, since the project was $100 \%$ funded by a national-E.U. co-funding call, the economic feasibility of the proposed system was not the crucial decision and design parameter.

\subsection{Practical Issues-Drawbacks}

The introduced solar-combi system, as shown above, is able to guarantee $100 \%$ annual heating loads coverage of the examined school building, with annual average heating production levelized cost lower than the corresponding feature of the existing oil-based central heating system. Yet, the proposed system exhibits some very specific practical issues, which, however, can be easily handled, as explained below:

- For six months per year, namely from mid-April to mid-October, the system will remain inoperative, due to the lack of any heating loads in the building, or any other thermal energy needs, as mentioned in the previous section. Due to this fact, in order to avoid over heating of the water in the thermal storage tanks, the solar collectors' transparent glazing should be covered with opaque textiles.

- A regular cleaning process for the solar collectors' glazing should be regularly applied, indicatively once a year, most probably at the beginning of the heating season.

- A regular cleaning of the biomass heater (removal of the combustion residue) should be also regularly performed, indicatively once a week. This is, objectively, the most demanding required task.

Finally, an appropriate infrastructure should be constructed, consisting of a large, outdoor biomass fuel closed tank and a duct, for the automatic refilling of a second, smaller silo inside the machinery room, from which the biomass heater will be supplied.

\section{Conclusions}

A solar-combi system was investigated in this article for the indoor space heating of a school building, located in the mainland of the island of Crete. The specific building exhibits two major favorable features, regarding the coverage of its heating loads from solar collectors:

- Firstly, there is considerable solar radiation available in the particular geographical location even during winter, a crucial issue for the maximisation of the building's heating loads coverage from solar collectors.

- Secondly, another important parameter, perhaps not so obvious, is the intermittent operation of the school building. This operational feature has a considerable contribution to the achievement of high coverage percentages of the building's heating loads from the solar collectors. Specifically, the lack of heating loads after the end of the school's daily operation schedule, on the one hand contributes to the reduction of the building's heating loads (no heating loads are considered during non-operational time periods), while, on the other hand, given the appropriate sizing of the thermal storage tanks, the thermal energy stored during non-operational periods, especially 
during the weekends, is utilized for the coverage of the forthcoming heating loads. In this way, the potential for high solar collectors' penetration to the annual thermal energy demand coverage is remarkably increased.

The two favorable parameters mentioned above enable the achievement of annual coverage percentages of the introduced solar collectors' field in the examined school building higher than $50 \%$, of course given the effective introduced algorithm and its adequate realization with the proposed system's overall layout.

On the other hand, the exclusive thermal energy consumption for the indoor space heating and the lack of any other thermal energy needs, has a negative impact on the economic feasibility of the examined system. The long payback period calculated at 19.50 years should be expected much shorter in case of a building with additional thermal energy needs (e.g., hot water consumption or longer operation period per day etc.).

The successful simulation and dimensioning of the examined system is also confirmed by the low surplus of the thermal energy produced from the solar collectors. This result should be absolutely expected too, given the large size of the building with the corresponding heating load and the, although still remarkable, reduced, compared to the summer period, available solar radiation. Nevertheless, all the favorable conditions mentioned above seem to be effectively exploited in the synthesis of the proposed system and the operation concept indicated with the introduced algorithm. The last step of course is the realization of the proposed system in the under consideration school building and the confirmation in practice of the simulation results of the present article.

In any case, the present article demonstrates a specific layout and operation algorithm for a solar-combi system, as well as the way this system can be realized and its automatic operation can be performed. Beyond any technical aspect, it certainly demonstrates the feasibility of $100 \%$ heating loads coverage in buildings, based on R.E.S. (solar radiation and biomass), especially in Southern European climates. This can be achieved with absolutely competitive production levelized cost, which, in the case of the examined case study, ranges at $0.154 € / \mathrm{kWh}_{\text {th }}$. This cost is lower than the corresponding figure with the use of a diesel oil central heater for the heating of the same school building, calculated at $0.1570 € / \mathrm{kWh}_{\text {th }}$.

Author Contributions: Conceptualization, D.A.K.; methodology, D.A.K. and G.Z.; software, D.A.K. and G.Z.; validation, D.A.K. and G.Z.; formal analysis, D.A.K. and G.Z.; investigation, D.A.K.; resources, D.A.K. and G.Z.; data curation, G.Z.; writing-original draft preparation, D.A.K.; writing-review and editing, D.A.K.; visualization, D.A.K.; supervision, D.A.K.; project administration, D.A.K.

Funding: This research received no external funding.

Acknowledgments: The authors of this study gratefully acknowledge the assistance and the contribution of Gareth Owens, for his contribution to the linguistic integrity of the article.

Conflicts of Interest: The authors declare no conflict of interest.

\section{References}

1. U.S. Energy Information Administration. 2012 Commercial Buildings Energy Consumption Survey: Energy Usage Summary. Available online: https:/ /www.eia.gov/consumption/commercial/reports/2012/ energyusage/ (accessed on 1 November 2018).

2. Behar, O. Solar thermal power plants-A review of configurations and performance comparison. Renew. Sustain. Energy Rev. 2018, 92, 608-627. [CrossRef]

3. Gorjian, S.; Ghobadian, B. Solar thermal power plants: Progress and prospects in Iran. Energy Procedia 2015, 75, 533-539. [CrossRef]

4. Cunio, L.N.; Sproul, A.B. Performance characterisation and energy savings of uncovered swimming pool solar collectors under reduced flow rate conditions. Sol. Energy 2012, 86, 1511-1517. [CrossRef]

5. Bunea, M.; Perers, B.; Eicher, S.; Hildbrand, C.; Bony, J.; Citherlet, S. Mathematical modelling of unglazed solar collectors under extreme operating conditions. Sol. Energy 2015, 118, 547-561. [CrossRef] 
6. Soltau, H. Testing the thermal performance of uncovered solar collectors. Sol. Energy 1992, 49, $263-272$. [CrossRef]

7. Hashim, W.M.; Shomran, A.T.; Jurmut, H.A.; Gaaz, T.S.; Al-Amiery, A.A. Case study on solar water heating for flat plate collector. Case Stud. Therm. Eng. 2018, 12, 666-671. [CrossRef]

8. Pandey, K.M.; Chaurasiya, R. A review on analysis and development of solar flat plate collector. Renew. Sustain. Energy Rev. 2017, 67, 641-650. [CrossRef]

9. Hao, W.; Lu, Y.; Lai, Y.; Yu, H.; Lyu, M. Research on operation strategy and performance prediction of flat plate solar collector with dual-function for drying agricultural products. Renew. Energy 2018, 127, 685-696. [CrossRef]

10. Tian, Z.; Perers, B.; Furbo, S.; Fan, J. Thermo-economic optimization of a hybrid solar district heating plant with flat plate collectors and parabolic trough collectors in series. Energy Convers. Manag. 2018, 165, 92-101. [CrossRef]

11. Nitsas, M.T.; Koronaki, I.P. Experimental and theoretical performance evaluation of evacuated tube collectors under Mediterranean climate conditions. Therm. Sci. Eng. Prog. 2018, 8, 457-469. [CrossRef]

12. Shafieian, A.; Khiadani, M.; Nosrati, A. A review of latest developments, progress, and applications of heat pipe solar collectors. Renew. Sustain. Energy Rev. 2018, 95, 273-304. [CrossRef]

13. Daghigh, R.; Shafieian, A. Theoretical and experimental analysis of thermal performance of a solar water heating system with evacuated tube heat pipe collector. Appl. Therm. Eng. 2016, 103, 1219-1227. [CrossRef]

14. Sabiha, M.A.; Saidur, R.; Mekhilef, S.; Mahian, O. Progress and latest developments of evacuated tube solar collectors. Renew. Sustain. Energy Rev. 2015, 51, 1038-1054. [CrossRef]

15. Lamnatou, C.; Cristofari, C.; Chemisana, D.; Canaletti, J.L. Building-integrated solar thermal systems based on vacuum-tube technology: Critical factors focusing on life-cycle environmental profile. Renew. Sustain. Energy Rev. 2016, 65, 1199-1215. [CrossRef]

16. Hassanien, R.; Hassanien, E.; Li, M.; Tang, Y. The evacuated tube solar collector assisted heat pump for heating greenhouses. Energy Build. 2018, 169, 305-318. [CrossRef]

17. Shafii, M.B.; Mamouri, S.J.; Lotfi, M.M.; Mosleh, H.J. A modified solar desalination system using evacuated tube collector. Desalination 2016, 396, 30-38. [CrossRef]

18. Tyagi, V.V.; Kaushik, S.C.; Tyagi, S.K. Advancement in solar photovoltaic/thermal (PV/T) hybrid collector technology. Renew. Sustain. Energy Rev. 2012, 16, 1383-1398. [CrossRef]

19. Abdelrazik, A.S.; Al-Sulaiman, F.A.; Saidur, R.; Ben-Mansour, R. A review on recent development for the design and packaging of hybrid photovoltaic/thermal (PV/T) solar systems. Renew. Sustain. Energy Rev. 2018, 95, 110-129. [CrossRef]

20. Parvez Mahmud, M.A.; Huda, N.; Farjana, S.H.; Lang, C. Environmental impacts of solar-photovoltaic and solar-thermal systems with life-cycle assessment. Energies 2018, 11, 2346. [CrossRef]

21. Kefalloniti, I.; Ampatzi, E. Building integration of domestic solar combi-systems: The importance of managing the distribution pipework. Energy Build. 2017, 142, 179-190. [CrossRef]

22. Glembin, J.; Haselhorst, T.; Steinweg, J.; Rockendorf, G. Simulation and evaluation of solar thermal combi systems with direct integration of solar heat into the space heating loop. Energy Procedia 2016, 91, 450-459. [CrossRef]

23. Antoniadis, C.N.; Martinopoulos, G. Simulation of solar thermal systems with seasonal storage operation for residential scale applications. Procedia Environ. Sci. 2017, 38, 405-412. [CrossRef]

24. Yang, Z.; Wang, Y.; Li, Z. Building space heating with a solar-assisted heat pump using roof-integrated solar collectors. Energies 2011, 4, 504-516. [CrossRef]

25. Kalder, J.; Annuk, A.; Allik, A.; Kokin, E. Increasing solar energy usage for dwelling heating, using solar collectors and medium sized vacuum insulated storage tank. Energies 2018, 11, 1832. [CrossRef]

26. Katsaprakakis, D.A.; Zidianakis, G. Upgrading energy efficiency for school buildings in Greece. Procedia Environ. Sci. 2017, 38, 248-255. [CrossRef]

27. Kyriaki, E.; Giama, E.; Papadopoulou, A.; Drosou, V.; Papadopoulos, A.M. Energy and environmental performance of solar thermal systems in hotel buildings. Procedia Environ. Sci. 2017, 38, 36-43. [CrossRef]

28. Calise, F.; Figaj, R.D.; Vanoli, L. Energy and economic analysis of energy savings measures in a swimming pool centre by means of dynamic simulations. Energies 2018, 11, 2182. [CrossRef]

29. Katsaprakakis, D.A. Comparison of swimming pools alternative passive and active heating systems based on renewable energy sources in Southern Europe. Energy 2015, 81, 738-753. [CrossRef] 
30. Hsieh, S.; Omu, A.; Orehounig, K. Comparison of solar thermal systems with storage: From building to neighbourhood scale. Energy Build. 2017, 152, 359-372. [CrossRef]

31. Tirumala, N.; Kumar, U.; Martin, A.R. Co-production performance evaluation of a novel solar combi system for simultaneous pure water and hot water supply in urban households of UAE. Energies 2017, 10, 481. [CrossRef]

32. Bois, J.; Mora, L.; Wurtz, E. Energy saving analysis of a solar combi-system using detailed control algorithm modeled with Modelica. Energy Procedia 2015, 78, 1985-1990. [CrossRef]

33. Deng, S.; Dai, Y.J.; Wang, R.Z. Performance optimization and analysis of solar combi-system with carbon dioxide heat pump. Sol. Energy 2013, 98, 212-225. [CrossRef]

34. D'Antoni, M.; Ferruzzi, G.; Bettoni, D.; Fedrizzi, R. Validation of the numerical model of a turnkey solar combi + system. Energy Procedia 2012, 30, 551-561. [CrossRef]

35. Johansen, J.B.; Englmair, G.; Dannemand, M.; Kong, W.; Furbo, S. Laboratory testing of solar combi system with compact long term PCM heat storage. Energy Procedia 2016, 91, 330-337. [CrossRef]

36. Englmair, G.; Dannemand, M.; Johansen, J.B.; Kong, W.; Dragsted, J.; Furbo, S.; Fan, J. Testing of PCM heat storage modules with solar collectors as heat source. Energy Procedia 2016, 91, 138-144. [CrossRef]

37. Colclough, S.; McGrath, T. Net energy analysis of a solar combi system with Seasonal Thermal Energy Store. Appl. Energy 2015, 147, 611-616. [CrossRef]

38. Ma, Z.; Bao, H.; Roskilly, A.P. Feasibility study of seasonal solar thermal energy storage in domestic dwellings in the UK. Sol. Energy 2018, 162, 489-499. [CrossRef]

39. Andersen, E.; Furbo, S. Theoretical variations of the thermal performance of different solar collectors and solar combi systems as function of the varying yearly weather conditions in Denmark. Sol. Energy 2009, 83, 552-565. [CrossRef]

40. Hellenic National Meteorological Service: Meteorological Stations in Crete: Kasteli Pediados. Available online: http://hnms.gr/emy/el/observation/sa_teleytaies_paratiriseis_stathmou?perifereia=Crete\&poli= Kasteli_Pediados (accessed on 22 November 2018).

41. Kreider, J.; Rabl, A.; Curtiss, P. Heating and Cooling of Buildings, 3rd ed.; CRC Press: Boca Raton, FL, USA, 2017.

42. Official Governmental Gazette 2367B' /12-7-2017. Directive on Buildings' Energy Performance. Available online: http://tdm.tee.gr/wp-content/uploads/2017/07/fek_12_7_2017_egrisi_kenak.pdf (accessed on 4 January 2019).

43. 2009 ASHRAE Handbook-Fundamentals (SI Edition); American Society of Heating, Refrigerating and Air-Conditioning Engineers, Inc.: Atlanta, GA, USA, 2009.

44. Duffie, J.A.; Beckman, W.A. Solar Engineering of Thermal Processes, 4th ed.; Wiley: New York, NY, USA, 2013. 